\title{
Desempenho de cultivares de batata em solo infestado com Ralstonia solanacearum, raça 1.
}

\author{
Alice Maria Quezado-Duval; Carlos Alberto Lopes. \\ Embrapa Hortaliças, Caixa Postal 218, 70.359-970 Brasília - DF.
}

\section{RESUMO}

A reação de 28 cultivares de batata à murcha-bacteriana causada por Ralstonia (Pseudomonas) solanacearum, raça 1, biovar I, foi avaliada na Embrapa Hortaliças, Brasília (DF), no período de maio a agosto de 1998. O ensaio foi realizado em solo naturalmente infestado, em blocos ao acaso com três repetições e parcelas de seis plantas perfazendo $2,4 \mathrm{~m}^{2}$. As cultivares Cruza $148 \mathrm{e}$ Achat (resistentes) e Bintje (suscetível) foram utilizadas como controles. Foram feitas oito avaliações semanais da incidência da doença, iniciando-se 22 dias após o plantio, quando apareceram os primeiros sintomas, para o cálculo da Área Abaixo da Curva de Progresso da Doença (AACPD). Utilizando-se a análise de agrupamento, foi possível a distinção de cinco grupos quanto aos níveis de resistência/ suscetibilidade. As cultivares que apresentaram menores níveis de doença (grupo I: AACPD de 0,00 a 256,90) foram Cruza 148, Cruza 148 mutante, Araucária e Granola, que também tiveram as maiores produtividades comercial (tubérculos $>50 \mathrm{~mm}$ de diâmetro) e total (13,3 e 25,1 t/ha; 10,4 e 21,9 t/ha; 11,4 e 18,8 t/ha e 14,6 e 16,4 t/ha, respectivamente). Uma correlação significativa negativa $(\mathrm{P}<0,01)$ foi observada entre AACPD e produtividade comercial $(r=-0,76)$ e entre AACPD e produtividade total $(r=-0,83)$.

Palavras-Chave: Solanum tuberosum, Pseudomonas solanacearum, murcha-bacteriana, resistência.

\author{
ABSTRACT \\ Performance of potato cultivars in soil naturally infested with \\ race 1 of Ralstonia solanacearum.
}

Twenty-eight potato cultivars were evaluated for resistance to bacterial wilt caused by Ralstonia solanacearum, race 1, biovar I, from May to August, 1998, at Embrapa Hortaliças. The trial was carried out in a naturally infested field in a randomised complete block design with three replications and six plants per plot of 2.4 $\mathrm{m}^{2}$. 'Cruza 148' and 'Achat' (resistant), and 'Bintje' (susceptible) were used as controls. Disease incidence was assessed for eight weeks starting 22 days after planting, when the first symptoms were observed. The areas under the disease progress curves (AUDPC) were calculated and the cluster analysis performed using the unweighted pair-group method by arithmetic averages (UPGMA) and simple Euclidian distance coefficient. Five clusters of resistance/ susceptibility levels were defined. 'Cruza 148', 'Cruza 148 mutant', 'Araucaria' and 'Granola' had the lowest levels of disease and belonged to cluster 1 (AUDPC values from 0.00 up to 256.90). These cultivars also had the highest commercial (tubers $>50 \mathrm{~mm}$ diameter) and total yields (13.3 and 25.1 t/ha; 10.4 and $21.9 \mathrm{t} / \mathrm{ha} ; 11.4$ and 18.8 t/ha, and 14.6 and 16.4 t/ha, respectively). Negative significant correlations $(\mathrm{P}<0.01)$ were found between AUDPC and commercial yield $(r=-0.76)$ and AUDPC and total yield $(r=-0.83)$.

Keywords: Solanum tuberosum, Pseudomonas solanacearum, bacterial wilt, resistance.

\section{(Aceito para publicação em 20 de agosto de 1999)}

\begin{abstract}
A murcha-bacteriana, causada por Ralstonia solanacearum, é uma das doenças mais importantes da cultura da batata (Solanum tuberosum L.) no Brasil. É a principal causa da rejeição de campos de certificação de batata-semente onde o nível de tolerância dessa doença é zero (0) e causa perdas de até $50 \%$ na produção de tubérculos para consumo, inviabilizando áreas de cultivo pela longa persistência do patógeno no solo (Lopes et al., 1990; Lopes et al. 1993).

Duas raças, a raça 1 e a raça 3 , podem infectar a cultura da batata (Hayward, 1991). A raça 3 ("raça da batata"), embora não exclusiva, é a que prevalece nas principais áreas produtoras de batata do país, situadas nas regiões Sul e Sudeste. A raça 1 ("raça das solanáceas"), que está amplamente distribuída, aumen-
\end{abstract}

ta de importância à medida que as fronteiras de produção de batata se expandem para áreas tropicais como o cerrado do Brasil Central (French, 1994; Lopes \& Buso, 1997). O emprego de cultivares com algum nível de resistência é considerado uma medida importante para o desenvolvimento de estratégias de controle da murcha-bacteriana. Medidas preventivas de controle, como o uso de batata-semente certificada, plantio em áreas sem histórico de ocorrência da doença e rotação de culturas também devem ser utilizadas (French, 1994).

Alguns clones e cultivares possuindo resistência parcial à murchabacteriana têm sido identificados no Programa de Manejo Integrado da Murcha-bacteriana, do Centro Internacional de la Papa (CIP), Lima, Peru, do qual a
Embrapa Hortaliças é colaboradora (CIP, 1993; CIP, 1995; Lopes et al., 1997; Quezado-Soares et al., 1997). A cultivar Achat, apesar de não ter sido desenvolvida em programas de melhoramento visando resistência à murchabacteriana, tem sua baixa taxa de condenação em campos de certificação atribuída aos níveis superiores de resistência apresentados tanto em estados onde predomina a raça 3 , como em testes comparativos realizados no infectário infestado pela raça 1, da Embrapa Hortaliças (Lopes \& Quezado-Soares, 1995). Este fato explica parcialmente a sua boa aceitação por parte dos produtores, fazendo com que ela seja atualmente uma das mais plantadas no país.

Esse trabalho teve como objetivo avaliar cultivares de batata nacionais e 
Tabela 1. Incidência de murcha-bacteriana 70 dias após o plantio (IMB), valores de área abaixo da curva de progresso da doença (AACPD), porcentagem de tubérculos com sintomas (TS) e produtividades comercial (PC) e total (PT) em cultivares de batata. Brasília-DF, Embrapa Hortaliças, 1998.

\begin{tabular}{|c|c|c|c|c|c|c|c|}
\hline № & Cultivares & Origem & IMB $(\%)^{1}$ & $\mathrm{AACPD}^{2}$ & TS $(\%)^{3}$ & PC (t/ha) ${ }^{4}$ & PT (t/ha) \\
\hline 1 & Achat & Alemanha & 44,43 & 963,60 & $23,21^{(26 / 112)}$ & 1,82 & 3,22 \\
\hline 2 & Agria & Holanda & 100,00 & 2463,97 & $58,49^{(31 / 53)}$ & 0,78 & 1,44 \\
\hline 3 & Araucária & Brasil & 16,67 & 175,23 & $16,85^{(46 / 273)}$ & 11,35 & 18,79 \\
\hline 4 & Astrid & Alemanha & 83,33 & 2274,58 & $51,51^{(34 / 66)}$ & 0,39 & 1,67 \\
\hline 5 & Atlantic & EUA & 66,63 & 1499,12 & $42,10^{(8 / 19)}$ & 1,35 & 1,56 \\
\hline 6 & Baraka & Holanda & 33,33 & 777,70 & $30,00^{(24 / 80)}$ & 4,94 & 5,92 \\
\hline 7 & Baronesa & Brasil & 58,90 & 1310,98 & $77,78^{(28 / 36)}$ & 2,36 & 2,81 \\
\hline 8 & Bintje & Holanda & 83,33 & 1978,95 & $52,72^{(29 / 55)}$ & 0,74 & 1,64 \\
\hline 9 & Bronka & Polônia & 100,00 & 2255,87 & $100,00^{(15 / 15)}$ & 0,00 & 0,00 \\
\hline 10 & Catucha & Brasil & 72,20 & 1877,45 & $54,00^{(27 / 50)}$ & 1,71 & 2,29 \\
\hline 11 & Ciklamen & Hungria & 76,67 & 1198,33 & $31,69(45 / 142)$ & 3,75 & 6,55 \\
\hline 12 & Contenda & Brasil & 61,13 & 2676,35 & $66,67^{(8 / 12)}$ & 0,39 & 0,56 \\
\hline 13 & Cristal & Brasil & 93,33 & 1365,23 & $58,49(31 / 53)$ & 0,58 & 1,31 \\
\hline 14 & Cruza 148 & México & 0,00 & 0,00 & $13,03(34 / 261)$ & 13,31 & 25,07 \\
\hline 15 & Cr.148 mutante ${ }^{5}$ & Itália & 0,00 & 0,00 & $1,80(6 / 334)$ & 10,40 & 21,93 \\
\hline 16 & Desirée & Holanda & 77,77 & 1828,05 & $60,00(75 / 125)$ & 2,64 & 4,17 \\
\hline 17 & Erna & Alemanha & 62,23 & 1314,72 & $76,28(74 / 97)$ & 0,17 & 1,39 \\
\hline 18 & Estima & Holanda & 80,57 & 1662,62 & $64,71^{(44 / 68)}$ & 0,52 & 1,44 \\
\hline 19 & Grão Mogol ${ }^{6}$ & Brasil & 34,43 & 642,02 & $34,84^{(123 / 353)}$ & 0,00 & 5,62 \\
\hline 20 & Granola & Alemanha & 24,47 & 256,90 & $17,73^{(25 / 141)}$ & 14,56 & 16,42 \\
\hline 21 & J aette Bintje & Holanda & 76,67 & 1940,63 & $63,16^{(60 / 95)}$ & 1,44 & 1,67 \\
\hline 22 & Monalisa & Holanda & 44,43 & 1019,08 & $19,35^{(18 / 93)}$ & 0,00 & 3,17 \\
\hline 23 & Monte Bonito & Brasil & 33,33 & 847,52 & $21,55^{(53 / 246)}$ & 4,33 & 11,61 \\
\hline 24 & Recent & Holanda & 100,00 & 2534,98 & $41,67^{(5 / 12)}$ & 0,00 & 0,19 \\
\hline 25 & Rheinhort & Alemanha & 67,77 & 1519,03 & $9,61^{(5 / 52)}$ & 3,11 & 4,53 \\
\hline 26 & Roxy & Alemanha & 52,80 & 1293,83 & $24,34(28 / 115)$ & 3,13 & 6,28 \\
\hline 27 & Santé & Holanda & 88,87 & 2480,38 & $92,40^{(73 / 79)}$ & 0,11 & 0,31 \\
\hline 28 & Serrana & Argentina & 72,23 & 1711,15 & $60,94^{(39 / 64)}$ & 3,06 & 3,69 \\
\hline
\end{tabular}

1. Plantas com mais de $50 \%$ da folhagem murcha foram contadas como doentes para o cálculo da incidência da murcha-bacteriana (IMB). Dados representam média de três repetições, parcela de seis plantas;

2. AACPD: Área Abaixo da Curva do Progresso da Doença, calculada a partir da incidência da murcha-bacteriana em oito avaliações usando o programa computacional AACPD (Luiz A. Maffia, Universidade Federal de Viçosa, Viçosa-MG. Dados representam média de três repetições, parcela de seis plantas;

3. TS: Porcentagem de tubérculos com sintomas de podridão provocada por Ralstonia solanacearum (valores entre parênteses: numerador = número de tubérculos com sintomas; denominador = número de tubérculos produzidos com e sem sintomas, em três repetições, seis plantas/ parcela);

${ }^{4}$. PC: Produção comercial (tubérculos com diâmetro > $50 \mathrm{~mm}$ );

5. Cruza 148 mutante = Clone CIP 720118.1 (37-35A) mutante da cultivar Cruza 148 (CIP 720118) produzido na Itália para eliminar a pigmentação da polpa (CIP, 1995);

6. Genótipo antigo, sem procedência definida, fornecida pelo Instituto Agronômico de Campinas, coletada no município de Grão Mogol, MG. 
exóticas, plantadas ou não no país, quanto ao nível de resistência/suscetibilidade à murcha-bacteriana causada pela raça 1 de $R$. solanacearum.

\section{MATERIAL E MÉTODOS}

$\mathrm{O}$ ensaio foi instalado no infectário do campo experimental da Embrapa Hortaliças, Brasília, DF, no período de maio a agosto de 1998. O infectário, naturalmente infestado pela raça 1 , biovar I, de Ralstonia solanacearum, vem sendo utilizado para avaliações de clones de batata para resistência à murcha-bacteriana por mais de 15 anos. Aos 35 dias após o plantio, foi realizada a amontoa e, aos 90 dias, a colheita dos tubérculos sem sintomas para cálculo da produtividade comercial (tubérculos > $50 \mathrm{~mm}$ de diâmetro).

Foram avaliadas 28 cultivares, incluindo 'Achat' e 'Cruza 148' (padrões de resistência) e 'Bintje' (padrão de suscetibilidade). $\mathrm{O}$ delineamento experimental utilizado foi em blocos ao acaso com três repetições e seis plantas por parcela. $\mathrm{O}$ espaçamento empregado foi de $0,30 \mathrm{~m}$ entre plantas $\mathrm{x} 0,80 \mathrm{~m}$ entre linhas, tendo a parcela a área útil de 2,4 $\mathrm{m}^{2}$. A avaliação da doença foi feita com base na incidência, sendo consideradas doentes as plantas que apresentavam mais de $50 \%$ da folhagem murcha. Foram feitas oito avaliações semanais, iniciadas aos 22 dias após o plantio, quando se verificou o aparecimento dos primeiros sintomas. Os dados de incidência foram utilizados para o cálculo da Área Abaixo da Curva de Progresso da Doença (AACPD) pelo programa computacional AACPD (Luís A. Maffia, Universidade Federal de Viçosa, MG). Os valores médios de AACPD foram utilizados para a análise de agrupamento pelo programa FITOPAC (George Shepherd, Universidade de Campinas, SP), empregando-se o coeficiente distância euclidiana simples e o método da média de grupo. A escolha do número de grupos de níveis de resistência foi baseada na distribuição das variedades controles. Foi feita a análise de correlação entre AACPD e produtividades comercial e total.

As temperaturas registradas durante o período do ensaio foram considera-

Tabela 2. Grupos de níveis de resistência à murcha-bacteriana baseados nos valores médios das Áreas Abaixo da Curva de Progresso da Doença (AACPD) e cultivares de batata posicionadas em cada grupo. Brasília-DF, Embrapa Hortaliças, 1998.

\begin{tabular}{cccc}
\hline Grupo $^{1}$ & $\begin{array}{c}\text { Intervalos de } \\
\text { AAC PD }\end{array}$ & Cultivares $^{\mathbf{3}}$ & $\begin{array}{c}\text { Posição das } \\
\text { cultivares } \\
\text { controle }\end{array}$ \\
\hline 1 & $0,00-256,90$ & $14,15,3,20$ & Cruza 148 $(0,00)$ \\
2 & $642,02-1019,08$ & $19,6,23,1,22$ & Achat $(963,60)$ \\
3 & $1198,33-1314,72$ & $11,26,7,13,5,17$ & - \\
4 & $1519,03-1978,95$ & $25,18,28,16,10,21,8$ & Bintje $(1978,95)$ \\
5 & $2255,87-2676,35$ & $9,4,2,27,24,12$ & - \\
\hline
\end{tabular}

${ }^{1}$. Definido pela análise de agrupamento (coeficiente distância euclidiana simples, método média de grupo);

${ }^{2}$. Intervalos de valores de AACPD que definem cada grupo;

${ }^{3}$. Cultivares posicionadas em cada grupo. Utilizou-se a numeração da tabela 1 , sendo as cultivares dispostas pelos valores crescentes das AACPD.

das apropriadas para o desenvolvimento da doença, com temperaturas média mínima e média máxima de $14,5^{\circ} \mathrm{C}$ e $28,1^{\circ} \mathrm{C}$, respectivamente. A irrigação foi feita por aspersão convencional, de acordo com a necessidade da cultura.

\section{RESULTADOS E DISCUSSÃO}

A incidência da doença no último dia da avaliação, aos 71 dias do plantio, variou de $0 \%$, nas cultivares mais resistentes Cruza 148 e Cruza 148 mutante, a $100 \%$ de plantas murchas, registrada nas cultivares Agria, Bronka e Recent (Tabela 1).

Por meio da análise de agrupamento, foi possível a distinção de cinco grupos quanto aos níveis de resistência/ suscetibilidade (Tabela 2). As cultivares que apresentaram menores níveis de doença e que posicionaram-se no grupo I (AACPD de 0,0 à 256,9), foram Cruza 148, Cruza 148 mutante, Araucária e Granola (Tabela 2). Essas cultivares foram também as que tiveram as maiores produtividades comercial e total $(13,3$ e 25,1 t/ha; 10,4 e 21,9 t/ha; 11,4 e 18,8 t/ha e 14,6 e 16,4 t/ha, respectivamente) (Tabela 1). Uma correlação negativa significativa $(\mathrm{P}<0,01)$ foi observada entre AACPD e produtividade comercial $(r=-0,76)$ e entre AACPD e produtividade total $(r=-0,83)$.

Apesar de terem apresentado incidência zero (0) de murcha-bacteriana, as cultivares Cruza 148 e Cruza 148 mutante produziram tubérculos com sin- tomas de podridão provocados por $R$. solanacearum (34 tubérculos em $261 \mathrm{e}$ seis tubérculos em 334, respectivamente) (Tabela 1). 'Cruza 148' não possui bom padrão comercial, com tubérculos desuniformes e pigmentados tanto na película como na polpa, caracteres que têm alta herdabilidade (Tung, 1990a), o que o desqualifica como bom progenitor em programas de melhoramento. 'Cruza 148 mutante' é um genótipo mutante da Cruza 148, produzido na Itália, que aparentemente apresenta todas as características morfológicas de 'Cruza 148', com exceção da pigmentação da polpa (CIP, 1995). Esta cultivar apresentou comportamento semelhante à 'Cruza 148' quanto à incidência da murcha-bacteriana, tendo sido também a mais resistente, juntamente com 'Cruza 148', dentre 23 clones avaliados no Peru, em 1993-1994 (CIP, 1995). Este é, portanto, um genótipo que, apesar de vários inconvenientes devido a características comerciais, pode ser usado em cruzamentos visando resistência à murcha-bacteriana.

As cultivares Grão Mogol, Baraka, Monte Bonito e Monalisa se posicionaram com a cultivar Achat no grupo II (AACPD 642,02 - 1019,08) (Tabela 2). 'Achat' mostrou maiores níveis de doença do que os observados em testes anteriores, quando alternavase com a 'Cruza 148' em termos de resistência (Lopes \& Quezado Soares, 1995). Este fato se deve à interação do patógeno e da hospedeira com fatores 
ambientais (French \& De Lindo, 1982; Schmiediche, 1985; Tung et al., 1990a; Tung et al., 1990b). Conforme indicado por Melo \& Buso (1997), 'Achat' não é indicada para plantios sujeitos a temperaturas elevadas, como observado no período do ensaio (média das temperaturas máximas acima de $28^{\circ} \mathrm{C}$ ).

Tung et al. (1990a e 1990b) comprovaram que genes para adaptação em batata estão envolvidos na manifestação da resistência à murcha-bacteriana, tendo a função de estabilizar a expressão dos genes de resistência. Esta constatação pode explicar a resistência de Araucária, Baraka, Monte Bonito e Monalisa, cultivares mais bem adaptadas a climas mais quentes, consistindo, portanto, boas opções para cultivo na região do Brasil Central, onde predomina a raça 1 de $R$. solanacearum. Deve ser ressaltado, ainda, o fato de Araucária ser caracterizada como suscetível à murcha-bacteriana na Região Sul, onde predomina a raça 3 (IAPAR, 1997).

Um nível insatisfatório de resistência em cultivares com boas características comerciais; o fato de 'Achat' não florescer e, portanto não poder ser usada como genitor, e as características indesejáveis de 'Cruza 148' e 'Cruza 148 mutante' indicam claramente a necessidade de se continuar a busca por melhores genótipos para servirem como genitores em programas de melhoramento para resistência à murcha-bacteriana. $\mathrm{O}$ teste de fontes de resistência e dos materiais melhorados deve ser feito em diferentes regiões para se avaliar a possibilidade de uma "quebra" da resistência devido à variabilidade do patógeno e à falta de adaptabilidade do genótipo a uma determinada condição climática.

\section{AGRADECIMENTOS}

Os autores agradecem a Arione S. Pereira, da Embrapa Clima Temperado, Pelotas; a Hilário Miranda Filho, do IAC, Campinas e a Odone Bertoncini e Élcio Hirano, da Embrapa Sementes Básicas, Canoinhas, pelo fornecimento dos tubérculos de algumas cultivares utilizadas neste trabalho. A Luiz A. Maffia pelo fornecimento do programa de estatística.

\section{LITERATURA CITADA}

CIP (Lima, Peru). Integrated control of potato bacterial wilt. Program Report CIP 19931994, Lima, p. 66-70, 1995.

CIP (Lima, Peru). Integrated control of potato bacterial wilt. CIP in 1992: Program Report CIP, Lima, p. 48-51, 1993.

FRENCH, E.R. Strategies for integrated control of bacterial wilt of potatoes. In: HAYWARD, A.C.; HARTMAN, G.L., ed. Bacterial wilt: the disease and its causative agent, Pseudomonas solanacearum. Wallingford: CAB International, 1994. p.199-207.

FRENCH, E.R.; DE LINDO, L. Resistance to Pseudomonas solanacearum in potato: specificity and temperture sensivity. Phytopathology, v. 72, p. 1408-1412, 1982.

HAYWARD, A.C. Biology and epidemiology of bacterial wilt caused by Pseudomonas solanacearum. Annual Review of Phytopatholy, v. 29, p. 65-87,1991.

IAPAR (Curitiba, Paraná). IAPAR 82 : Araucária, cultivar de batata resistente a doenças foliares. Curitiba, 1997. Folder.

LOPES, C.A.; BUSO, J.A. Cultivo da batata (Solanum tuberosum). Brasília: EMBRAPACNPH, 1997. 35 p. (EMBRAPA-CNPH. Instruções Técnicas da Embrapa Hortaliças, 8).

LOPES, C.A.; BUSO, J.A.; ACCATINO, P. Screening CIP potato germplasm for resistance to bacterial wilt in Brazil: methods and preliminary results. Bacterial Wilt Newsletter, n. 9 , p. $3-5,1993$.
LOPES, C.A.; HIDALGO, O.A.; BUSO, J.A Melhoramento genético para resistência à murcha-bacteriana causada por Pseudomonas solanacearum no Brasil. In: HIDALGO, O.A.; RINCON, H., ed. Avances en el mejoramiento genetico de la papa en los Paises del cono Sur. Lima: CIP, 1990. p. 173-177.

LOPES, C.A.; QUEZADO-SOARES, A.M. Estabilidade da resistência da batata 'Achat' à murcha-bacteriana. Horticultura Brasileira, Brasília, v. 13, p. 57-58, 1995.

LOPES, C.A.; QUEZADO-SOARES, A.M.; BUSO, J.A.; MELO, P.E. Breeding for resistance to bacterial wilt of potatoes in Brasil. In: PRIOR, P.; ALLEN, C.; ELPHINSTONE, J., ed. Bacterial wilt disease: molecular and ecological aspects. Berlin: Springer Verlag, 1997. p. 290-293.

MELO, P.E.; BUSO, J.A. Principais variedades. In: LOPES, C.A.; BUSO, J.A., ed. Cultivo da batata (Solanum tuberosum L.). Brasilia: EMBRAPA-CNPH, 1997. 36 p. (EMBRAPACNPH. Instruções Técnicas da Embrapa Hortaliças, 8).

QUEZADO-SOARES, A.M.; LOPES, C.A.; BUSO, J.A.; MELO, P.E. Evaluation in Brazil of potato clones resistant to bacterial wilt in the Philippines. Bacterial Wilt Newsletter, $\mathrm{n}$. 14, p. 1-3, 1997.

SCHMIEDICHE, P. Breeding bacterial wilt, Pseudomonas solanacearum, resistant germplasm. In: PLANNING CONFERENCE ON PRESENT AND FUTURE STRATEGIES FOR POTATO BREEDING AND IMPROVEMENT, 1985, Lima, Peru. Report... Lima: CIP, 1985. p.45-55.

TUNG, P.X.; RASCO JUNIOR, E.T.; VANDER ZAAG, P.; SCHMIEDICHE, P. Resistance to Pseudomonas solanacearum in the potato. I. Effects of sources of resistance and adaptation. Euphytica, v. 45, p. 203-210, 1990a.

TUNG, P.X.; RASCO JUNIOR, E.T.; VANDER ZAAG, P.; SCHMIEDICHE, P. Resistance to Pseudomonas solanacearum in the potato. II. Aspects of host-pathogen-environment interaction. Euphytica, v. 45, p. 211-215, $1990 \mathrm{~b}$ 